The war on prevention II: Battle metaphors undermine cancer treatment and prevention and do not increase vigilance

\author{
David J. Hauser \\ Queen's University \\ Department of Psychology, Craine 320, 56 Arch St, Kingston, ON K7L 3L3, Canada; \\ david.hauser@queensu.ca \\ @DavidJHauser
}

Norbert Schwarz

University of Southern California

USC Dornsife Mind \& Society Center, 205 VPD, 635 Downey Way, Los Angeles, CA 90089-

3331, USA; norbert.schwarz@usc.edu

in press at Health Communication

Word count: 4690 words

Please address all correspondence to David J. Hauser, Queen's University, Department of

Psychology, Craine 320, 56 Arch St, Kingston, ON K7L 3L3, Canada; david.hauser@queensu.ca 


\begin{abstract}
Bellicose metaphors for cancer are ubiquitous. But are they good metaphors for health communicators to use? Because metaphors can guide reasoning about abstract concepts, framing cancer with metaphors of battle, war, and enemies leads people to apply attributes of these concepts to cancer. The current research investigates how this affects inferences about cancer treatment, prevention, and monitoring. Battles and war are usually seen as being difficult. Indeed, reading about a person's "battle" or "fight" against cancer makes cancer treatment seem more difficult (studies 1-4). One way to approach a battle is to surrender and give up control. Consistent with this implication, battle metaphors increase fatalistic beliefs about cancer prevention (e.g., believing that there is little one can do to prevent getting cancer; study 3). Finally, even though battles invoke vigilance and action, Study 4 failed to find that such metaphors motivate people to immediately see their doctor when imagining a cancer scare. These findings suggest that bellicose metaphors for cancer can influence the health beliefs of nonpatients in ways that may make them less willing to enact healthy behaviors. keywords: metaphoric framing, cancer, treatment, difficulty, beliefs $<179$ / 200 words $>$
\end{abstract}




\section{The war on prevention II: Battle metaphors undermine cancer treatment and prevention and do not increase vigilance}

Bellicose metaphors for cancer are ubiquitous. Books frame healthy foods as foods that "fight cancer" (Beliveau \& Gringras, 2006). Media portray cancer treatments as "ammunition in the war against cancer" (Time Magazine, May $28^{\text {th }}, 2001$ ). And popular discourse describes cancer patients as "battling” the disease (Sontag, 1978).

But are these the right metaphors to use? Some patients find them to be apt descriptors for their experience, but others do not (Reisfield \& Wilson, 2004). Health professionals describe cancer less often with violence metaphors than do patients (Semino et al., 2017), suggesting that health experts may find battle metaphors to be less apt descriptors. Because metaphors have the potential to affect beleifs and behaviors, understanding their potential influence in this domain is important. Conceptual metaphor theory (Lakoff \& Johnson, 1980) suggests that metaphors shape reasoning about abstract concepts. When a concept is metaphorically-framed, attributes of the source metaphor are made relevant to the concept. Framing crime as a beast that rampages cities causes people to propose more punitive solutions to a crime wave (Thibodeau \& Boroditsky, 2011), and framing climate change as a war causes people to view it with more urgency, increasing their willingness to behave in environmentally-friendly ways (Flusberg, Matlock, \& Thibodeau, 2017). Metaphors can guide reasoning and shape behavior. Thus, a major question for health communication is: Do bellicose metaphors make people think of cancer in a way that could promote healthy or unhealthy behavior?

Some research suggests that applying fighting metaphors to disease can help people in certain ways. Playing a video game where protagonists virtually battle cancer has been shown to increase treatment adherence in young cancer patients (Kato, Cole, Bradlyn, \& Pollock, 2008). 
Health information that describes the flu metaphorically as an aversive entity (a beast, a riot, an army, or a weed) increases people's willingness to get vaccinated (Scherer, Scherer, \& Fagerlin, 2015), and pamphlets that frame the sun as a hostile entity increase people's willingness to wear sunblock, particularly when they fear hostility (Landau, Arndt, \& Cameron, 2018). Indeed, some cancer patients who use violence metaphors do so in a way that suggests personal agency and pride in being a fighter, and some communities of patients find solidarity in being "fighters" (Semino et al., 2017).

However, other research suggests that fighting metaphors can also hurt. For instance, reading health information about cancer that frames it as an enemy makes people less likely to think of certain cancer prevention behaviors and reduces their intention for limiting behaviors that increase cancer risk (Hauser \& Schwarz, 2015). Reading about a patient's "battle" with cancer encourages the inference that the patient feels guilty if treatment doesn't go well (Hendricks, Demjen, Semino, \& Boroditsky, 2018). Finally, some cancer patients use violence metaphors in a way that suggests feeling disempowered and defeated by the disease (Semino et al., 2017).

These metaphor effects are consistent with conceptual metaphor theory and the attributes of battles with enemies. Fighting entails risk, which motivates people to curtail it and builds solidarity among all those facing the same threat. At the same time, if one must "fight" cancer, this presumes that prevention has not worked, and it puts one at risk of "losing" the fight and experiencing all the negative emotions associated with it. This suggests that prominent attributes of battles are likely to come to mind whenever cancer is framed in terms of battle metaphors. Battles have many attributes that may be relevant to cancer treatment, prevention, and monitoring. Some of these attributes may have positive effects on health beliefs, while others 
may have negative effects. For instance, one prominent attribute of battles and war is difficulty. Common sayings (such as the "strain of war") emphasize its difficulty, and many of the most frequent adjective collocates of the word "battle" in the Corpus of Contemporary American English (COCA; Davies, 2008) relate to difficulty: uphill, bitter, fierce, epic, bloody, hardfought. Similarly, cancer treatment is often said to be difficult. Chemotherapy patients often experience emotional distress and aversive side effects that diminish quality of life (Love, Leventhal, Easterling, \& Nerenz, 1989). Similarly, some of the most frequent adjective collocates of the word "chemotherapy" in COCA (Davies, 2008) highlight its aversive nature: aggressive, intensive, toxic. Because battles as well as cancer treatment can be thought of as difficult, framing cancer treatment as a battle may seem natural. However, this framing is likely to further enhance perceptions of its difficulty, and simply reading these metaphors in health information may encourage such perceptions.

Perceiving treatment to be difficult may have noteworthy consequences for non-patients. As observed in persuasion research, highlighting the difficulty and aversiveness of a particular health condition creates fear (Hovland, Janis, \& Kelley, 1953). If a message does this while also offering plausible suggestions for how to avoid the feared condition, it can persuade and motivate recipients to enact healthy behaviors (Witte \& Allen, 2000). However, battle metaphors for cancer rarely do this, instead simply rallying people to "fight cancer" or profiling cancer “survivors" without offering plausible suggestions for how to curtail one's own risk. Without such suggestions, fear appeals can negatively impact persuasion, in some circumstances, causing recipients to avoid the information or react against it (Earl \& Albarracin, 2007). It is therefore important to know whether battle metaphors increase the perceived difficulty of cancer treatment. 
As discussed above, battle metaphors may also guide inferences about cancer prevention. Battles rarely involve prevention, and one way to approach a battle is to yield, give up control, and surrender to the attacker. Similarly, many believe that they lack control in preventing cancer, a belief called cancer fatalism (for a review, see Powe \& Finnie, 2003). People high in cancer fatalism believe that they have no personal control in preventing the disease - no matter what they do, they'll get it if they were meant to. Thus, framing cancer as a battle could also prompt "surrender" to cancer, encouraging many to adopt more fatalistic attitudes toward cancer prevention. This could have negative consequences for public health because people with high cancer fatalism are less likely to get screened for breast cancer (Conrad, Brown, \& Conrad, 1996), less likely to comply with mammography recommendations (Mayo, Ureda, \& Parker , 2001), and less likely to have regular pap smears (Chavez, Hubbell, Mishra, \& Valdez, 1997).

Finally, battle metaphors may also affect beliefs about cancer monitoring. Battles involve vigilance, surveying the battlefield for possible signs of attackers, and raising the alarm when one is seen. Similarly, cancer monitoring involves surveilling the body for warning signs of the disease, and seeing a doctor if a symptom emerges. Thus, framing cancer as a battle could also prompt people to be more vigilant about monitoring, causing them to act rather than delay when facing a warning sign. In contrast to the previously-hypothesized negative effects of these metaphors, these hypothesized effects would be beneficial because not everyone is so vigilant. When some people experience a symptom that may be indicative of cancer, they delay visiting a healthcare professional, instead monitoring their symptoms for a change (Facione, Miaskowski, Dodd, \& Paul, 2002). The optimal choice is to act and visit immediately because this delay can increase morbidity (Katz, Hislip, Thomas, \& Larson, 1993).

The current research is designed to assess how battle metaphors affect inferences about 
treatment, prevention, and monitoring for nonpatients. Conceptual metaphor theory suggests that metaphoric frames should highlight metaphor-consistent attributes of concepts (Lakoff \& Johnson, 1980). However, metaphoric framing does not necessarily ensure that inferences will be influenced; effects could be absent for a variety of reasons. If a metaphor is not seen as being apt, it hinders processing, and inferences are unaffected (Thibodeau \& Durgin, 2011). If an inference doesn't seem applicable to the metaphorical problem, then the metaphor has no impact (Landau, et al., 2018). Further, if a conceptual metaphor is chronically accessible, metaphor framing will not have an observable effect because it only activates an already active conceptual metaphor. These conditions parallel familiar prerequisites for the emergence of concept accessibility effects in the social judgment literature (for a review, see Schwarz \& Lee, 2019).

\section{Present research}

Four studies test whether battle metaphors affect inferences related to the perceived difficulty of treatment, fatalistic aspects of prevention, and vigilance for monitoring. In Studies 1 through 4, nonpatients read about another person's cancer diagnosis, which was described as either being a fight/battle with cancer or was described in other ways. Then participants rated how difficult they expected that person's cancer treatment to be. Because battles are difficult, we expected participants who saw battle metaphors (vs control metaphors) to rate that person's cancer treatment as being more difficult.

Study 3 additionally investigates how battle metaphors affect beliefs about prevention. After reading about another person's battle (vs journey) with cancer, participants also completed a scale of cancer fatalism. Because battles often involve surrendering control, we expected that participants who read battle (vs journey) metaphors would have more fatalistic beliefs about cancer prevention. 
Study 4 addresses how battle metaphors affect monitoring intentions. After reading about another person's battle (vs journey) with cancer, participants also completed a scale that assessed to what extent they would delay seeing a doctor in the event of a cancer scare. Because battles involve monitoring and vigilance, we expected that participants who read battle (vs journey) metaphors would have less delay in seeing a doctor.

\section{Methods}

Because of the similarity in designs, we first describe the methods of each study (characteristics of the participants, procedures, and materials), followed by reviewing their results. Studies 1 through 4 investigate the effect of battle metaphors on perceptions of the difficulty of treatment. Study 3 also sheds light on the effect of battle metaphors on cancer fatalism. And Study 4 examines the effect of battle metaphors on monitoring intentions. We report all studies, manipulations, measures, and exclusions. All materials, data, and analysis scripts can be found at https://osf.io/k2zhe/.

\section{Study 1 - difficulty}

Participants. Based on prior research (Hauser \& Schwarz, 2015), we sought an $N=200$ to achieve $80 \%$ power for detecting a minimum effect size of $d=.40$ (Faul, Erdfelder, Land, \& Buchner, 2007). Two hundred and seven American workers from Amazon Mechanical Turk (MTurk) initiated the study in exchange for 30 cents. Following current best-practice recommendations, workers were required to have 100 prior accepted HITs and a HIT acceptance ratio of $95 \%$ or higher, and were required to not have completed any of our prior surveys on metaphors for cancer (Hauser, Paolacci, \& Chandler, 2019). These eligibility criteria were used for all studies reported.

Three participants read the informed consent sheet and dropped out. Eight participants 
were excluded because they took over ten minutes to complete the survey, exceeding the mean completion time by more than 2.5 standard deviations (Wood, Harms, Lowman, \& DeSimone, 2017); their exclusion was independent of experimental condition. This left us with a final sample of 196 participants (91 female; age range $18-71)$.

Procedure. Participants were directed to an online survey on thoughts about cancer treatment and were randomly assigned to conditions. They first read a description of a person's cancer diagnosis, which did vs. did not contain battle metaphors for cancer. The description follows, with words in parenthesis appearing in the battle metaphor vignette and words in brackets appearing in the no metaphor vignette:

Tomorrow, Susan Eckersby will meet with her doctor and they will discuss how they will [treat her cancer] (fight the cancer that has invaded and attacked her body). Two weeks ago, she was diagnosed with a (malignant) differentiated ductal carcinoma, requiring treatment. Susan is a mother of two girls, eight and five years old, and she is a school bus driver.

After reading this vignette, participants answered questions about Susan's treatment in the order presented below. They first estimated how many weeks the treatment would take from beginning to full recovery (free response). Next, they rated how much control they thought Susan had over whether she recovers or not $(1=$ very little control, $7=$ a great deal of control $)$ and how much effort they thought Susan would put into her recovery $(1=$ very little effort, $7=$ a great deal of effort). These measures were included as conceptual replications of effects observed by Hendricks and colleagues (2018); however, message metaphor had no effects on these measures, so we excluded them from subsequent studies.

Participants then indicated on seven-point scales how difficult, grueling, arduous, and 
exhausting Susan's treatment would be ( 1 = slightly, $7=$ extremely; difficulty index $\alpha=.90)$.

Finally, participants completed demographic information (age, gender, major, ESL status), indicated if they know people who have gone through cancer treatment (yes/no), rated their knowledge of cancer ( 1 = I know very little, 7 = I know very much), and were debriefed.

\section{Study 2 - difficulty}

Participants. Three hundred and fifty-eight American workers from MTurk initiated the study in exchange for 30 cents. Two workers read the informed consent sheet and dropped out. We excluded the data of six participants with duplicate IP addresses (a sign of repeated participation) and of nine participants who took over 5.6 minutes to complete the survey (exceeding the mean completion time by more than 2.5 standard deviations). These exclusions were independent of condition. This left us with a final sample of 341 participants (172 female; age range $18-87)$.

Procedure. Participants read the above vignette (containing either enemy metaphors or no metaphors, randomly assigned) and rated how difficult, grueling, arduous, and exhausting Susan's treatment would be ( $1=$ slightly, $7=$ extremely; difficulty index $\alpha=.91)$. This replicates Study 1 without the questions that preceded these ratings of treatment burden. Finally, they completed demographic questions and were debriefed.

\section{Study 3 - difficulty and fatalism}

Participants. Two hundred and thirty-six American workers from MTurk initiated the study in exchange for 40 cents. Two workers dropped out before completing the difficulty measures, leaving us with a final sample of 234 participants who completed these measures (83 female; age range $19-72$ ).

This survey also included a later measure of cancer fatalism. A total of 36 participants 
(15\%) dropped out of the survey before completing this measure. Attrition marginally-differed between metaphor conditions - 23 participants (19\% of the group) who read the battle metaphor dropped out whereas 13 participants (11\% of the group) who read the journey metaphor dropped out, $\chi^{2}(1, N=236)=3.28, p=.070$. However, we suspect that the likelihood of attrition does not correlate with responses to the crucial dependent variable and that our conclusions are warranted despite attrition (Deke \& Chiang, 2007). After attrition, we were left with a final sample of 200 participants who completed the cancer fatalism measure (82 female; age range $19-72$ ).

Procedure. Study 3 utilized a different description of a cancer diagnosis (from Hendricks et al., 2018). It was manipulated to either contain enemy metaphors for cancer or journey metaphors for cancer (randomly assigned). The description read:

Joe has cancer, and he knows that for the foreseeable future, every day will be a battle against (journey with) the disease. The battle (road) he has to fight (travel) will not always be an easy one. Many people have written about their experiences on the battlefield (path), and he can turn to those for consolation. His family and friends want him to know that he will not be alone in his battle (journey). Even though sometimes he might not feel like talking, other times he may want to share stories of his battle (journey) with others, and they will be there for those moments.

Following the vignette, participants rated how difficult, grueling, arduous, and exhausting Joe's battle/journey would be ( $1=$ slightly, $7=$ extremely; difficulty index $\alpha=.92)$. Next, participants responded to an open-ended prompt about what America should do to win the war on cancer (solve the cancer problem in America). Metaphor had no effects on this latter measure and it will not be discussed further. 
Then participants responded to 10 items (order randomized) assessing their level of cancer fatalism using a version of the predetermination subscale of Shen, Condit, and Wright (2009) that was modified to be specific to cancer. For instance, participants rated to what extent they agreed or disagreed with statements such as "If someone is meant to get cancer, they will get it no matter what they do" on 5 point scales $(1=$ strongly disagree, $2=$ slightly disagree, $3=$ neither agree nor disagree, $4=$ slightly agree, $5=$ strongly agree). Participants also responded to 3 items from Niederdeppe and Levy (2007) assessing cancer information overload (e.g., "It seems like everything causes cancer") but there were no effects of metaphor for these items so they will not be discussed further.

\section{Study 4 - difficulty and delay}

Participants. Two-hundred American workers from MTurk initiated the survey in exchange for 40 cents. None dropped out, leaving us with a final sample of 200 participants (98 female; age range $14-76)^{1}$.

Procedure. Participants first reported their demographic information, including their biological sex (male or female), age, etc. Then they read the Joe diagnosis vignette (containing either enemy or journey metaphors, randomly assigned). Following the vignette, participants rated how difficult, grueling, arduous, and exhausting Joe's battle/journey would be (1 = slightly, 7 = extremely; difficulty index $\alpha=.90$ ). Participants then responded to 15 items (order randomized) regarding whether they would delay in the event of a cancer scare (Facione, 2002). The scale was tailored to the biological sex that participants had previously selected:

When a woman (man) finds a change in her breast (his testicle) that concerns her (him), there are many things that she (he) might do. Read each statement

\footnotetext{
${ }^{1}$ We suspect that the participant who reported being 14 years old made a typo as MTurk does not allow workers under the age of eighteen.
} 
carefully. Think about what you might do if you discovered a breast (testicle) change that worried you. Mark YES or NO to show what you think you would do. Items included "I would go immediately into denial," and "I would try not to think about it." Participants responded YES or NO to each item. Participants also rated their agreement with two statements: "If I had a symptom that I thought might be cancer, I would be too frightened to seek medical advice" and "The earlier that cancer is detected, the greater chance I have of successful treatment" ( 1 = strongly disagree, $5=$ strongly agree). Finally, participants were debriefed.

\section{Results and discussion}

\section{Do battle metaphors make treatment seem more difficult?}

Because battles are difficult, we hypothesized that framing the vignette in terms of a battle metaphor would make treatment seem more difficult compared to control conditions with no metaphor or a journey metaphor. As shown in Table 1, the direction of all mean differences between conditions is consistent with this prediction. However, for each of the two vignettes the observed differences are only reliable in one out of two experiments. To assess these mixed results, we conducted a meta-analysis of these studies to estimate the average effect size and its reliability. 
Table 1. Individual study results for the effect of metaphor on perceived difficulty of cancer treatment.

\begin{tabular}{crrrc}
\hline Metaphor & $\mathrm{N}$ & Mean difficulty (SD) & $F$ & $p$ \\
\hline Study 1 & & & & \\
Battle & 100 & $6.18(0.86)$ & $F(1,194)=4.89$ & .028 \\
None & 96 & $5.91(0.84)$ & & \\
\hline Study 2 & & & & \\
Battle & 173 & $5.95(0.87)$ & $F(1,339)=0.88$ & .349 \\
None & 168 & $5.86(0.87)$ & & \\
\hline Study 3 & 118 & $6.12(0.97)$ & $F(1,232)=1.56$ & .213 \\
Battle & 116 & $5.96(0.99)$ & & \\
Journey & & & & \\
\hline Study 4 & 102 & $6.37(0.71)$ & $F(1,198)=9.40$ & .002 \\
Battle & 98 & $6.01(0.94)$ & & \\
Journey & & & & \\
\hline
\end{tabular}

Using the r package metafor (Viechtbauer, 2010), we first computed the standardized mean difference in perceived difficulty by metaphor for each study. In studies 1 and 2, this was battle vs no metaphor whereas in studies 3 and 4, this was battle vs journey metaphors. Because studies had similar designs and effects, we then used a fixed effect model to estimate the average effect size in the studies (Hedges \& Vevea, 1998). As shown in the forest plot in Figure 1, the meta-analysis showed a standardized mean effect of $0.23(S E=0.06, z=3.51, p<.001,95 \% \mathrm{CI}$ $[0.10,0.35]$ for the comparison of a battle metaphor vs control conditions. Overall, the data are consistent with the hypothesis that battle metaphors increase the perceived difficulty of cancer treatment. Because battles are difficult, framing treatment as a battle increases perceptions of its difficulty, potentially making people less receptive to health information about cancer (Earl \& Albarracin, 2007). 


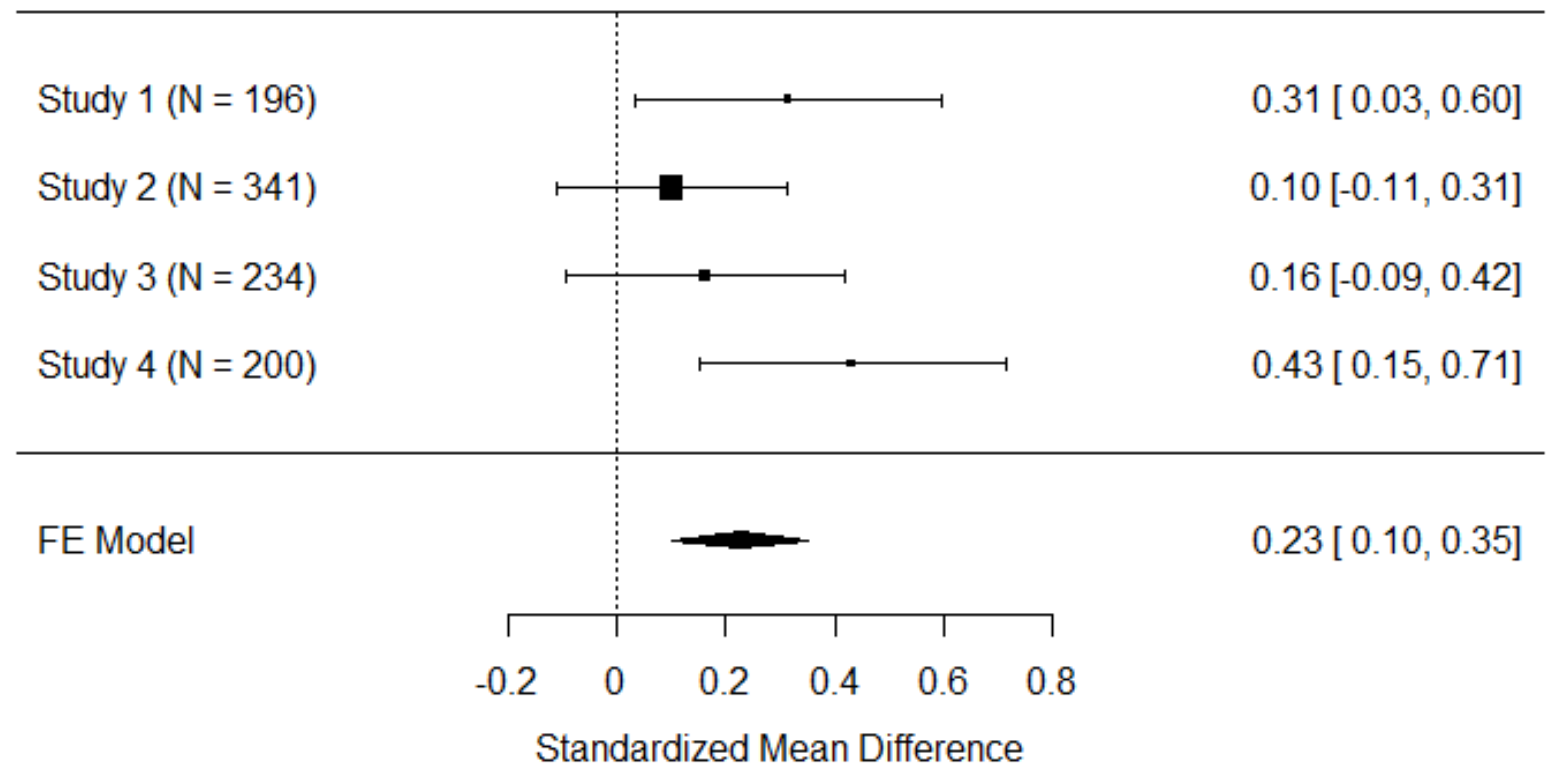

Figure 1. Forest plot of the standardized mean effect of battle metaphors for each study and fixed effects model for meta-analytic effect at bottom. Dot size represents sample size and bars represent $95 \%$ confidence intervals.

\section{Do battle metaphors increase cancer fatalism?}

In Study 3, all predetermination scale items (Shen et al., 2009) were averaged to form an index of each participant's beliefs of cancer fatalism $(\alpha=.90)$. Because battles can be surrendered, we hypothesized that battle metaphors would increase fatalistic beliefs about cancer prevention. This hypothesis was supported. Participants who read the profile that contained battle metaphors had more fatalistic beliefs about cancer $(M=2.53, S D=0.92)$ than participants who read the profile that contained journey metaphors $(M=2.24, S D=0.82), F(1,198)=5.71, p=$ $.018, r=.17,95 \%$ CI [0.03, 0.27]. Thus, battle metaphors change people's beliefs about cancer prevention. Reading about a person's "battle" with cancer increased participants fatalistic beliefs about cancer and its controllability. This is especially concerning because high cancer fatalism is associated with numerous negative health behaviors (for a review, see Powe \& Finnie, 2003). 


\section{Do battle metaphors decrease delay?}

In Study 4, we identified which participants were "delayers" according to the judgment delay scale. Facione (2002) recommended a conservative cut score of selecting three or more delaying behaviors as an indicator of a delayer and a liberal cut score of selecting one or more delaying behaviors. The conservative measure identified $31.5 \%$ of our sample as being delayers while the liberal measure identified $56.5 \%$ as delayers.

Because battles involve vigilance and action when a threat is detected, we expected that battle metaphors would lessen the number of participants who would delay seeing a doctor when imagining a cancer scare. However, battle metaphors had no effect on this scale of delay. Using the conservative cut score, participants who read battle metaphors were equally likely to delay seeking treatment as those who read journey metaphors (33\% battle delayers vs $30 \%$ journey delayers $), \chi^{2}(1, N=200)=.32, p=.569$. No differences emerged using the liberal cut score either $(59 \%$ battle delayers vs $54 \%$ journey delayers $), \chi^{2}(1, N=200)=.46, p=499$. Agreement with the statements "If I had a symptom that I thought might be cancer, I would be too frightened to seek medical advice" and "The earlier that cancer is detected, the greater chance I have of successful treatment" was also unaffected by metaphor, $p \mathrm{~s}<.185$.

Thus, this final study finds no evidence that people are more vigilant when thinking of cancer as an enemy to battle. This is especially noteworthy because i.) motivating people to take action is often the intention of these metaphors and ii.) monitoring is often a very effective prevention strategy (Katz et al., 1993).

\section{General Discussion}

While battle metaphors are ubiquitous in discourse on cancer, they may not be benign elements in cancer communication. The present studies show that framing cancer with battle 
metaphors i.) increases the perceived difficulty of cancer treatment, ii.) increases fatalism about cancer prevention, and iii.) does not increase vigilance in cancer monitoring.

These results have wide-ranging public health implications. While perceiving treatment to be more difficult is not negative itself, it has the potential to be demotivating. Research on fear appeals has long found that they backfire when they make a health condition seem especially aversive while offering no plausible avenues for preventing it; for instance, fear appeals for HIV increase perceptions of risk but decrease knowledge of the disease and preventative behavior when no information is given (Earl \& Albarracin, 2007). Similarly, we find that battle metaphors make cancer treatment seem more difficult (the current studies), which may motivate reactance against to the message (Witte \& Allen, 2000), which may, in turn, reduce the likelihood that message recipients will engage in preventative behavior (Hauser \& Schwarz, 2015). Thus, these metaphors shape people's thoughts about treatment in ways that may be detrimental to public health.

Additionally, in Study 3, reading about another person's "battle” with cancer increased the belief that cancer prevention is out of one's control, a phenomenon known to be associated with negative health behaviors such as neglecting breast cancer screening (Conrad et al., 1996), mammography noncompliance (Mayo et al., 2001), and neglecting pap smears (Chavez et al., 1997). This is consistent with our prior work showing that such metaphors lessen people's intentions to limit cancer-risk increasing behaviors (Hauser \& Schwarz, 2015). Battle metaphors seem to have unintended negative consequences for nonpatients, particularly for how they view cancer prevention - they make prevention seem less effective and lessen intention for it.

Finally, we hypothesized that because battles involve vigilance, framing cancer as a battle would make people more vigilant about addressing warning signs for cancer. However, Study 4 
failed to find that battle metaphors motivated people to immediately see their doctor when imagining a cancer scare. Thus, these metaphors do not motivate people to lessen delay, which greatly increases the morbidity of many cancers (Katz et al., 1993). However, the effect of battle metaphors on vigilance still deserves future research. Indeed, prior research has suggested that battle metaphors have motivating effects (Semino et al., 2017, Kato et al., 2008), but this work primarily focuses upon how they motivate patients rather than nonpatients. This suggests that there may be critical differences between patients and non-patients, such as knowledge of cancer, fear of cancer, or the simple accessibility of it in their lives, that serves as a boundary condition for the motivating influence of battle metaphors. For instance, patients who fear cancer may feel empowered by the metaphor, which motivates them to tackle the things they ought to do to remain healthy. On the other hand, nonpatients who have less worry of cancer may find the metaphor to be less apt, which likely makes it less empowering.

The current research does come with limitations. While the studies altogether demonstrated that battle metaphors increase the perceived difficulty of treatment, battle metaphors had no impact on responses to seemingly-related measures in Study 1 (estimates of length of treatment, control over recovery, and effort). We hesitate to make post-hoc theoretical explanations for why this may be, but it is important to note that the effects of metaphor on perceptions of difficulty did not reliably appear at the level of the individual study. Effects on these measures may more reliably appear with larger samples (see Hendricks et al., 2018, for effects of battle metaphors on conceptually-similar measures). Additionally, participants were primarily nonpatients, so our conclusions may not generalize to patient populations. As we outlined above, they may not apply to patient populations even for theoretical reasons, such as how patients and nonpatients differ in their level of worry about cancer. 
The current research demonstrates the importance of conceptual metaphor theory in health communication. The inner-workings of the body and disease are inherently abstract concepts with which people lack concrete, perceptual experience. Under such conditions, people rely on lay theories and conceptual metaphors for comprehension, which gives metaphors a key role in guiding people's medical decisions and health behaviors (Hauser, Nesse, \& Schwarz, 2017). Hence, the metaphors we use to frame health and disease have the power to influence public health in beneficial or harmful ways. It is therefore important to investigate the inferences that metaphors promote before entering them into public discourse or making them a central theme in health communications (Hauser \& Schwarz, 2016).

\section{Conclusion}

Framing cancer treatment as a battle increases perceptions of its difficulty. This could negatively affect the health beliefs of nonpatients, as fear of a health condition can cause people to avoid thinking about it and react against changing their lifestyle (Earl \& Albarracin, 2007). Such frames also increase fatalistic beliefs about prevention, which is associated with negative health behaviors (Powe \& Finnie, 2003), without motivating vigilance in cancer monitoring. War and battle metaphors are common ways of talking about cancer; FIGHT and BATTLE are in the top ten verbs to appear within 4 words in front of the word CANCER (in COCA; Davies, 2008, as analyzed in Hauser \& Schwarz, 2015). The frequent use of these words in public discourse about cancer can have negative implications for the health beliefs of the public. 


\section{References}

Beliveau R. \& Gingras, D. (2006). Foods that Fight Cancer: Preventing Cancer through Diet. Toronto, ON: McClelland \& Stewart.

Chavez, L. R., Hubbell, F. A., Mishra, S. I., \& Valdez, R. B. (1997). The influence of fatalism on self-reported use of Papanicolaou smears. American Journal of Preventive Medicine, 13, 418-424.

Conrad, M. E., Brown, P., \& Conrad, M. G. (1996). Fatalism and breast cancer in black women. Annals of Internal Medicine, 125, 941-942.

Davies, M. (2008). The Corpus of Contemporary American English: 450 million words, 1990present. Available online at http://corpus.byu.edu/coca/.

Deke, J., \& Chiang, H. (2017). The WWC attrition standard: Sensitivity to assumptions and opportunities for refining and adapting to new contexts. Evaluation Review, 41, 130-154.

Earl, A., \& Albarracín, D. (2007). Nature, decay, and spiraling of the effects of fear-inducing arguments and HIV counseling and testing: A meta-analysis of the short-and long-term outcomes of HIV-prevention interventions. Health Psychology, 26, 496-506.

Facione, N. C. (2002). The J-Delay scale: A measure of the likelihood of patient delay in breast cancer. Research and Theory for Nursing Practice, 16, 103-118.

Facione, N. C., Miaskowski, C., Dodd, M. J., \& Paul, S. M. (2002). The self-reported likelihood of patient delay in breast cancer: New thoughts for early detection. Preventive Medicine, 34, 397-407.

Faul, F., Erdfelder, E., Lang, A. G., \& Buchner, A. (2007). G* Power 3: A flexible statistical power analysis program for the social, behavioral, and biomedical sciences. Behavior Research Methods, 39, 175-191. 
Flusberg, S. J., Matlock, T., \& Thibodeau, P. H. (2017). Metaphors for the war (or race) against climate change. Environmental Communication, 11, 769-783.

Hauser, D. J. \& Schwarz, N. (2015). The war on prevention: Bellicose cancer metaphors hurt (some) prevention intentions. Personality and Social Psychology Bulletin, 41, 66-77.

Hauser, D. J. \& Schwarz, N. (2016). Medical metaphors matter: Experiments can determine the impact of metaphors on bioethical issues. American Journal of Bioethics, 16, 18-19.

Hauser, D. J., Nesse, R. M., \& Schwarz, N. (2017). Lay theories and metaphors of health and illness. In Zedelius C., Muller, B., \& Schooler J. W. (Eds.), The Science of Lay Theories: How Beliefs Shape our Culture, Cognition, and Health. (pp. 341-354). Springer.

Hauser, D. J., Paolacci, G., \& Chandler, J. (2019). Common concerns with MTurk as a participant pool: Evidence and solutions. In F. R. Kardes, P. M. Herr, \& N. Schwarz (Eds.), Handbook of Research Methods in Consumer Psychology. (pp. 319-337). Routledge.

Hedges L. V. \& Vevea J. L. (1998). Fixed- and random-effects models in meta-analysis. Psychological Methods, 3, 486-504.

Hendricks, R. K., Demjén, Z., Semino, E., \& Boroditsky, L. (2018). Emotional implications of metaphor: Consequences of metaphor framing for mindset about cancer. Metaphor and Symbol, 33, 267-279.

Hovland C. I., Janis I. L., \& Kelley H. H. (1953). Communication and Persuasion: Psychological Studies of Opinion Change. Yale University Press.

Kato, P. M., Cole, S. W., Bradlyn, A. S., \& Pollock, B. H. (2008). A video game improves behavioral outcomes in adolescents and young adults with cancer: A randomized trial. Pediatrics, 122, 305-317. 
Katz, S. J., Hislop, T. G., Thomas, D. B., \& Larson, E. B. (1993). Delay from symptom to diagnosis and treatment of breast cancer in Washington State and British Columbia. Medical Care, 31, 264-268.

Lakoff, G., \& Johnson, M. (1980). Metaphors We Live By. Chicago: University of Chicago Press.

Landau, M. J., Arndt, J., \& Cameron, L. D. (2018). Do metaphors in health messages work? Exploring emotional and cognitive factors. Journal of Experimental Social Psychology, $74,135-149$.

Love, R. R., Leventhal, H., Easterling, D. V., \& Nerenz, D. R. (1989). Side effects and emotional distress during cancer chemotherapy. Cancer, 63(3), 604-612.

Mayo, R. M., Ureda, J. R., \& Parker, V. G. (2001). Importance of fatalism in understanding mammography screening in rural elderly women. Journal of Women \& Aging, 13, 57-72.

Niederdeppe, J., \& Levy, A. G. (2007). Fatalistic beliefs about cancer prevention and three prevention behaviors. Cancer Epidemiology and Prevention Biomarkers, 16, 998-1003.

Powe, B. D., \& Finnie, R. (2003). Cancer fatalism: The state of the science. Cancer Nursing, 26, 454-467.

Reisfield, G. M., \& Wilson, G. R. (2004). Use of metaphor in the discourse on cancer. Journal of Clinical Oncology, 22, 4024-4027.

Scherer, A. M., Scherer, L. D., \& Fagerlin, A. (2015). Getting ahead of illness: Using metaphors to influence medical decision making. Medical Decision Making, 35, 37-45.

Schwarz, N., Lee, S.W.S. (2019). Embodied cognition and the construction of attitudes. In D. Albarracin \& B. T. Johnson (Eds.), The Handbook of Attitudes, Volume 1: Basic Principles: 2nd Edition. New York: Taylor \& Francis. 
Semino, E., Demjén, Z., Demmen, J., Koller, V., Payne, S., Hardie, A., \& Rayson, P. (2017). The online use of violence and journey metaphors by patients with cancer, as compared with health professionals: A mixed methods study. BMJ Supportive \& Palliative care, 7, 60-66.

Shen, L., Condit, C. M., \& Wright, L. (2009). The psychometric property and validation of a fatalism scale. Psychology and Health, 24, 597-613.

Sontag, S. (1978). Illness as Metaphor. New York, NY: Farrar, Straus \& Giroux.

Thibodeau, P. H., \& Boroditsky, L. (2011). Metaphors we think with: The role of metaphor in reasoning. PLoS One, 6 .

Thibodeau, P. H., \& Durgin, F. H. (2011). Metaphor aptness and conventionality: A processing fluency account. Metaphor and Symbol, 26, 206-226.

Time Magazine. (May 28 ${ }^{\text {th }}, 2001$ ). Drugs that fight cancer. Retrieved from http://content.time.com/time/covers/0,16641,20010528,00.html.

Viechtbauer, W. (2010). Conducting meta-analyses in R with the metafor package. Journal of Statistical Software, 36, 1-48.

Witte, K., \& Allen, M. (2000). A meta-analysis of fear appeals: Implications for effective public health campaigns. Health Education \& Behavior, 27, 591-615.

Wood, D., Harms, P. D., Lowman, G. H., \& DeSimone, J. A. (2017). Response speed and response consistency as mutually validating indicators of data quality in online samples. Social Psychological and Personality Science, 8, 454-464. 